\title{
44. 海水面上昇へのデルタの応答に関する研究
}

\author{
STUDY ON DELTA RESPONSE TO RISING SEA LEVEL
}

\author{
赤松良久*・Gary Parker** ・武藤鉄司*** \\ Yoshihisa AKAMATSU • Gary PARKER • Tetsuji MUTO
}

\begin{abstract}
Rivers form deltas wherever they flow into standing water such as a lake, a reservoir or the ocean. Under conditions of constant base level of standing water deltas can be expected to gradually prograde outward, so that the delta shoreline regresses "seaward." Rising base level can not only slow this progradation, but reverse it, so that the shoreline migrates landward, or transgresses. An extreme limit of this case is one of shoreline starvation, for which the supply of sediment at the shoreline drops to zero and the delta goes into transgressive autoretreat. A 1D morphodynamic model of delta response including backwater effect is developed to clarify the response of delta to sea level rise. The simulations revealed that the interaction between sediment supply and sea level rise determines whether or not a) the delta continues to prograde under conditions of sea level rise, or b) the delta begins to transgress and eventually goes into autoretreat.
\end{abstract}

Key Words : Delta, Morphodynamic Model, Sea Level Rise, Autoretreat

\section{1. はじめに}

約1.4万年前の最終水期以降, 海水面は毎年 $1 \mathrm{~cm}$ 以上の 速度で急激に上昇し, 約6000 7000年前に現在の海面と ほぼ同じレベルか, わずかに高いレベルまでに達した. その後, 何度かの海面の上昇および低下を繰り返し, 約 1000年前には現在の海水準とほぼ同じレベルに達し, 安 定的に推移してきた. しかし, 今日の地球温暖化により 今後急激な海水面の上昇が起こることが縣念されている. デルタはこのような海水面の上昇に対してどのように応 答するのであろうか?

河川からの土砂の供給により形成されるデル夕は海水 面が一定の場合には海域に進行し続ける. しかし，海水 面が上昇する場合には，土砂によって埋められるべき余 剩のスペースができるため, デル夕が後退する現象が起 こりうる. Muto and Steel (1992)は急激な海水面上昇によ りデルタの前部堆積層への土砂供給が無くなり, デル夕 全体が陸域に後退する現象を「Autoretreat」と名付けた. また, Muto (2001)は「Autoretreat」の概念を示すために, 非常に狭い水路において水位を上昇させながら上流端か ら土砂を供給する実験を行った（図ー1）.さらに,

Paker and Muto (2003)は「Autoretreat」に関する実験に対 して, 一次元の地形変動モデルを用いて再現計算を行っ た. 一次元の地形変動モデルは実験の再現を目的とした ものであり, 河川内の流れを考慮していないモデルであ

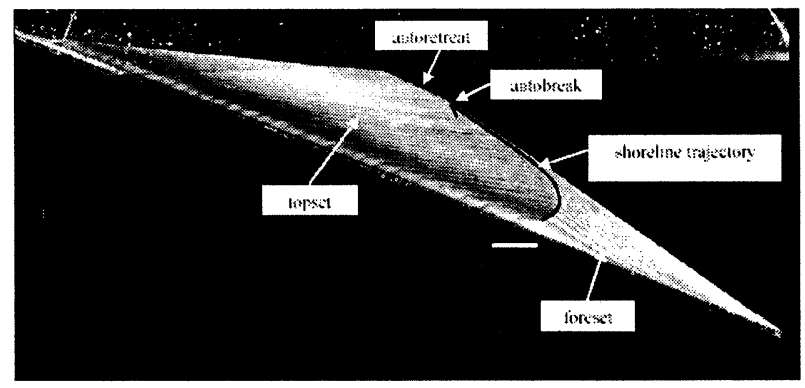

図-1 Muto(2001)の実験から得られた「Autoretreat」の概念図

るが, 実験においてみられた「Autoretreat」を再現でき ることがわかった.

そこで, 本研究では実スケールのデル夕に適応すべく， 河川水面の背水曲線等を考慮した一次元の地形変動モデ ルを構築し, 海水面上昇に対するデルタの応答について 検討した. さらに, デルタのスケールによる海水面上昇 に対する応答の違いについても検討した.

\section{2. 数値計算モデル}

本研究で用いるデルタの地形変動のモデルはSwenson et al. (2000)およびKostic and Parker (2003a,b)による研究を 参考としている. これらのモデルはデルタの進行を考慮 


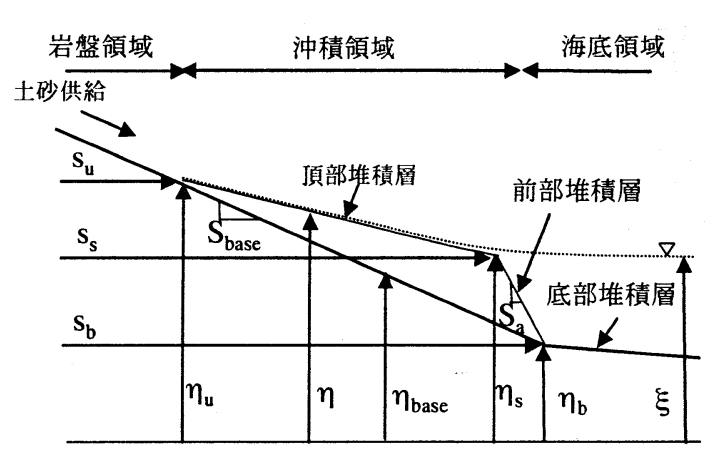

図-2 計算に用いるパラメーター

した移動境界を持つことが大きな特徵である. 本研究で は，デル夕の上流端が自由に移動する場合および上流端 が固定されている場合の二つのケースを考えている. 計 算に用いるパラメーターを図-2に示す.ここで, $\eta$ : 沖 積河床高, $\eta_{\text {base }}$ : 地盤高, $s$ : 水平方向の座標, $\xi$ : 海水 準, $\mathrm{S}_{\text {base }}$ : 地盤の勾配, $\mathrm{S}_{\mathrm{a}}$ : 前部堆積層の勾配である. (a) 流れの支配方程式 流れの支配方程式は以下のように表される.

$$
\mathrm{UH}=\mathrm{q}_{\mathrm{w}}
$$

$$
\frac{d}{d x}\left(U^{2} H\right)=-g H \frac{d H}{d x}+g H S-C_{f} U^{2}
$$

ここに, $\mathrm{x}$ :流れ方向の座標, $\mathrm{U}$ : 流れ方向の水深平均流 速, $\mathrm{H}$ : 水深, $\mathrm{g}$ : 重力加速度, $\mathrm{q}_{\mathrm{w}}$ : 単位幅流量, $\mathrm{S}$ : 河床 勾配, $\mathrm{C}_{\mathrm{f}}$ : 河床摩擦抵抗係数である. 河床勾配は以下の ように与えられる.

$$
S=-\frac{\partial \eta}{\partial x}
$$

本モデルにおいて河床摩擦抵抗係数は一定であると仮定 しており, 河床せん断応力は以下のように表される.

$$
\tau_{\mathrm{b}}=\rho \mathrm{C}_{\mathrm{f}} \mathrm{U}^{2}
$$

ここに, $\rho は$ 水の密度を表している. 式(3),(4)を用いて式 (1),(2)は以下のように変形できる.

$$
\begin{aligned}
U & =\frac{q_{w}}{H} \\
\frac{d H}{d x} & =\frac{S-S_{f}}{1-\mathrm{Fr}^{2}}
\end{aligned}
$$

ここに,

$$
\mathrm{Fr}=\frac{\mathrm{U}}{\sqrt{\mathrm{gH}}} \quad \mathrm{S}_{\mathrm{f}}=\mathrm{C}_{\mathrm{f}} \mathrm{Fr}
$$

である. 河川の流れは常流つまり $\mathrm{Fr}<1$ を仮定しており 式(6)の境界条件は $\mathrm{x}=\mathrm{s}_{\mathrm{s}}$ において以下のように与えられる.

$$
\left.\mathrm{H}\right|_{\mathrm{x}=\mathrm{s}_{\mathrm{s}}}=\xi-\eta_{\mathrm{s}}
$$

ここで, $\eta_{\mathrm{s}}=\eta\left(\mathrm{s}_{\mathrm{s}}, \mathrm{t}\right)$ である.

(b) 土砂保存式

河床の土砂保存はExnerの式を用いて次のように表さ れる.

$$
\mathrm{B}_{\mathrm{f}}\left(1-\lambda_{\mathrm{p}}\right) \frac{\partial \eta}{\partial \mathrm{t}}=-\mathrm{B} \frac{\partial \mathrm{Iq}_{\mathrm{t}}}{\partial \mathrm{x}}
$$

ここに, $\mathrm{B}_{\mathrm{f}}$ : 堆積盆地の幅, $\mathrm{B}$ : 河川幅（網状の場合は その合計） $\lambda_{p}$ : 堆積土砂の間隙率，I : 間欠度（実時間 に対する洪水時の有効時間の割合）, $\mathrm{q}_{\mathrm{t}}$ : 単位幅当たり の流砂量である. 一般的に掃流砂量の算定式は以下のよ うに表される.

$$
\mathrm{q}^{*}=\alpha_{\mathrm{t}}\left(\tau^{*}-\tau_{\mathrm{c}}^{*}\right)^{\mathrm{n}_{\mathrm{t}}}
$$

ここに， $\alpha_{t}$ および $\mathrm{n}_{\mathrm{t}}$ はパラメーターであり, $\mathrm{q}^{*}$ およ びで は以下のように定義される.

$$
\mathrm{q}^{*}=\frac{\mathrm{q}_{\mathrm{t}}}{\sqrt{\operatorname{RgDD}}} \quad \tau^{*}=\frac{\tau_{\mathrm{b}}}{\rho \operatorname{RgD}}
$$

ここに、 $\mathrm{R}$ は堆積土砂の水中比重を示す. また, 式(10a) 中の ${ }_{\mathrm{c}}{ }^{*}$ は移動限界の無次元掃流力を表す. Engelund and Hansen (1967) の全流砂量式では砂床河川に対して以下 のような値を用いるのが妥当である.

$$
\alpha_{\mathrm{t}}=\frac{0.05}{\mathrm{C}_{\mathrm{f}}} \quad \mathrm{n}_{\mathrm{t}}=2.5 \quad \tau_{\mathrm{c}}^{*}=0 \quad(11 \mathrm{a}, \mathrm{b}, \mathrm{c})
$$

沖積領域の上流端での土砂供給条件は以下のように与え られる.

$$
\left.\mathrm{q}_{\mathrm{t}}\right|_{\mathrm{x}=\mathrm{s}_{\mathrm{u}}}=\mathrm{q}_{\mathrm{tf}}
$$

でありここに， $\mathrm{q}_{\mathrm{Iff}}$ は上流端からの土砂供給量を示す.

(c) 移動境界における連続条件

岩盤領域と沖積領域の接点における連続条件は次によ うに表される.

$$
\eta_{\mathrm{u}} \equiv \eta\left[\mathrm{s}_{\mathrm{u}}(\mathrm{t}), \mathrm{t}\right]=\eta_{\text {base }}\left[\mathrm{s}_{\mathrm{u}}(\mathrm{t})\right]
$$

式(13)の時間微分をとり変形すると

$$
\underset{\mathrm{u}}{\mathrm{\&}}=-\left.\frac{1}{\mathrm{~S}_{\mathrm{base}}-\mathrm{S}_{\mathrm{u}}} \frac{\partial \eta}{\partial \mathrm{t}}\right|_{\mathrm{s}_{\mathrm{u}}}
$$

となる.ここで, ドットは時間微分であり， $\mathrm{S}_{\mathrm{u}}$ は沖積 領域の上流端での河床勾配を表す．ここに， $\mathrm{S}_{\mathrm{u}} \mathrm{S}_{\mathrm{base}}$ は以 下のように表される.

$$
\mathrm{S}_{\mathrm{u}}=-\left.\frac{\partial \eta}{\partial \mathrm{x}}\right|_{\mathrm{s}_{\mathrm{u}}}, \quad \mathrm{S}_{\text {base }}=-\frac{\partial \eta_{\text {base }}}{\partial \mathrm{x}}
$$

また, 前部堆積層と底部堆積層の接点においても式 (13)と同様に以下のような連続条件が成り立つ. 
$\eta_{\mathrm{b}} \equiv \eta\left[\mathrm{s}_{\mathrm{b}}(\mathrm{t}), \mathrm{t}\right]=\eta_{\mathrm{s}}-\mathrm{s}_{\mathrm{a}}\left(\mathrm{s}_{\mathrm{b}}-\mathrm{s}_{\mathrm{s}}\right)=\eta_{\text {base }}\left[\mathrm{s}_{\mathrm{b}}(\mathrm{t})\right](15)$

式(15)の時間微分をとり変形すると

$s=\frac{S_{a}-S_{s}}{S_{a}-S_{\text {base }}} s+\left.\frac{1}{S_{a}-S_{\text {base }}} \frac{\partial \eta}{\partial t}\right|_{s_{s}}, \quad S_{s}=-\left.\frac{\partial \eta}{\partial x}\right|_{s_{s}}$

となる. ここに, $\mathrm{S}_{\mathrm{s}}$ は海岸線（頂部堆積層と前部堆積層 の接点）での河床勾配を表す。

さらに, 前部堆積層と底部堆積層の接点において土砂 流出がないという条件の下で式(9)を前部堆積層の区間に おいて積分すると, 以下のような衝撃条件が得られる (Kostic and Parker, 2003a; Swenson et al., 2000).

$$
\underset{s}{\&}=\frac{1}{S_{a}-S_{s}}\left(\frac{q_{t f}}{s_{b}-s_{s}}-\left.\frac{\partial \eta}{\partial t}\right|_{s_{s}}\right)
$$

\section{ここで}

$$
\mathrm{q}_{\mathrm{ss}} \equiv \mathrm{q}_{\mathrm{s}}\left[\mathrm{s}_{\mathrm{s}}(\mathrm{t}), \mathrm{t}\right]
$$

である.

式(6)，(9)を式(14)，(16), (17)の条件の下で差分化して 数值計算を行う. 流れに関しては常流を仮定して, 下流 から上流へ計算を行い，土砂の保存式においては土砂供 給のある上流から下流に向けて計算を進める.

\section{3. 海水面上昇へのデルタの応答}

実スケールのデルタとして, 初期河川長 $\mathrm{L}=30(\mathrm{~km})$, 河川幅 $\mathrm{B}=100(\mathrm{~m})$, 洪水時満水流量 $\mathrm{Q}=600\left(\mathrm{~m}^{3} / \mathrm{s}\right)$, 洪水時 土砂供給量 $\mathrm{q}_{\mathrm{t} f=} 8.4$ (million metric tons/year), 堆積盆地幅 $\mathrm{B}_{\mathrm{f}}=1500(\mathrm{~m})$, 粒径 $\mathrm{D}=0.5(\mathrm{~mm})$, 間欠度 $\mathrm{I}=0.1$ のデル夕を想 定し, 海水面上昇に対するデル夕の応答に関して検討し た（本計算では上流端を固定境界としている）。図一 3(a)，(b) に海水面上昇率 $\mathrm{V}_{\mathrm{s}}$ が 0 (cm/year), および 1(cm/year)の二つのケースについて河床形態の変化を示 す.海水面上昇率がゼロの場合にはデル夕は前進し続け ている. しかし，海水面の上昇率が1 (cm/year) という高 い値をとる場合には, Muto(2001)の実験（図-1）同様に

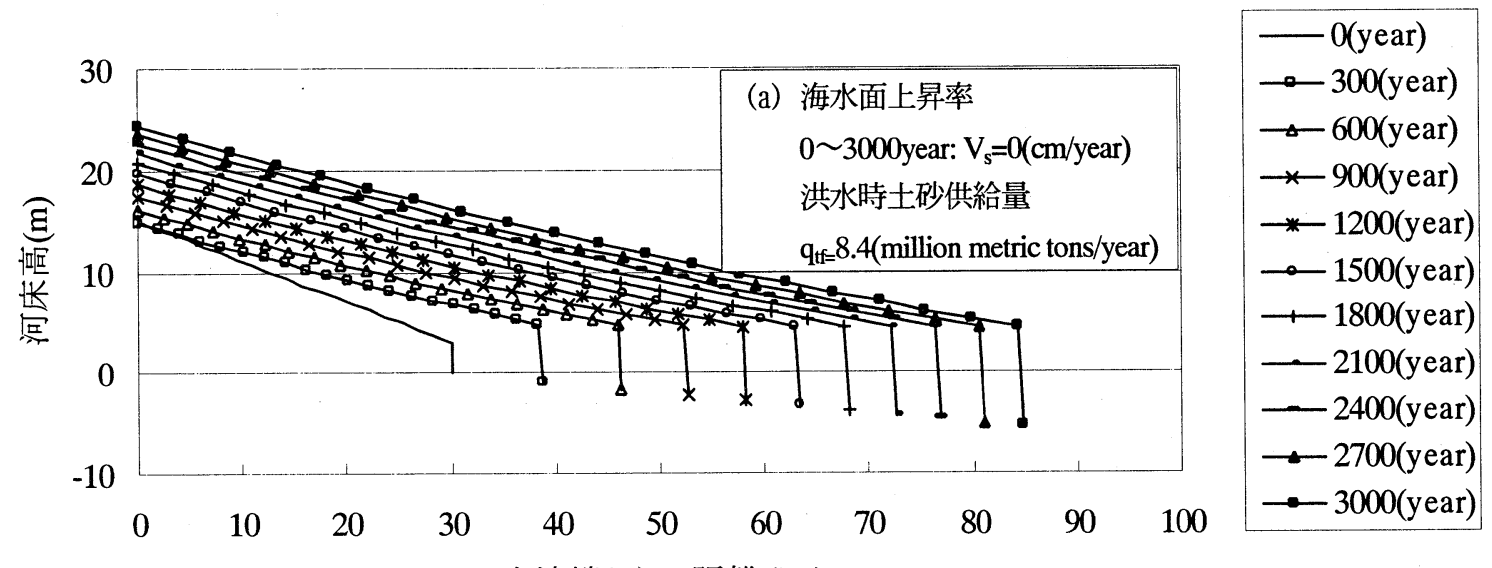

上流端からの距離 $(\mathrm{km})$

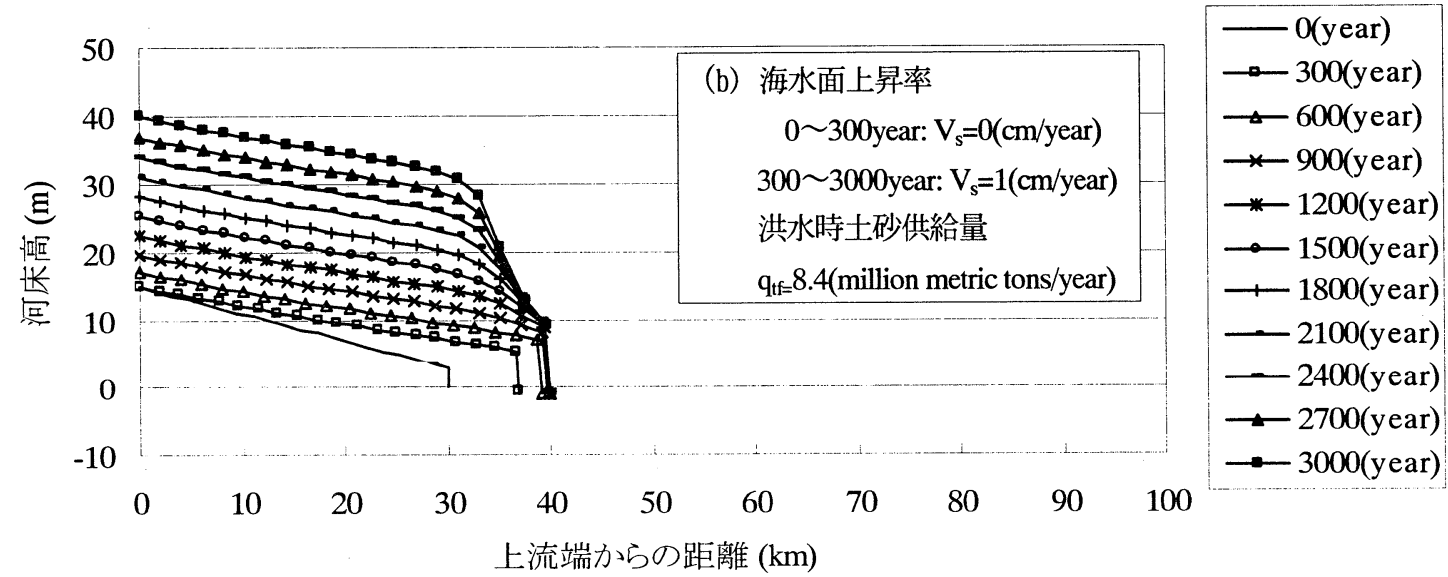

図-3 (a)，(b) 海水面上昇率が $0(\mathrm{~cm} / \mathrm{year})$ および 1 ( $\mathrm{cm} / \mathrm{year})$ の場合の河床形態の変化 


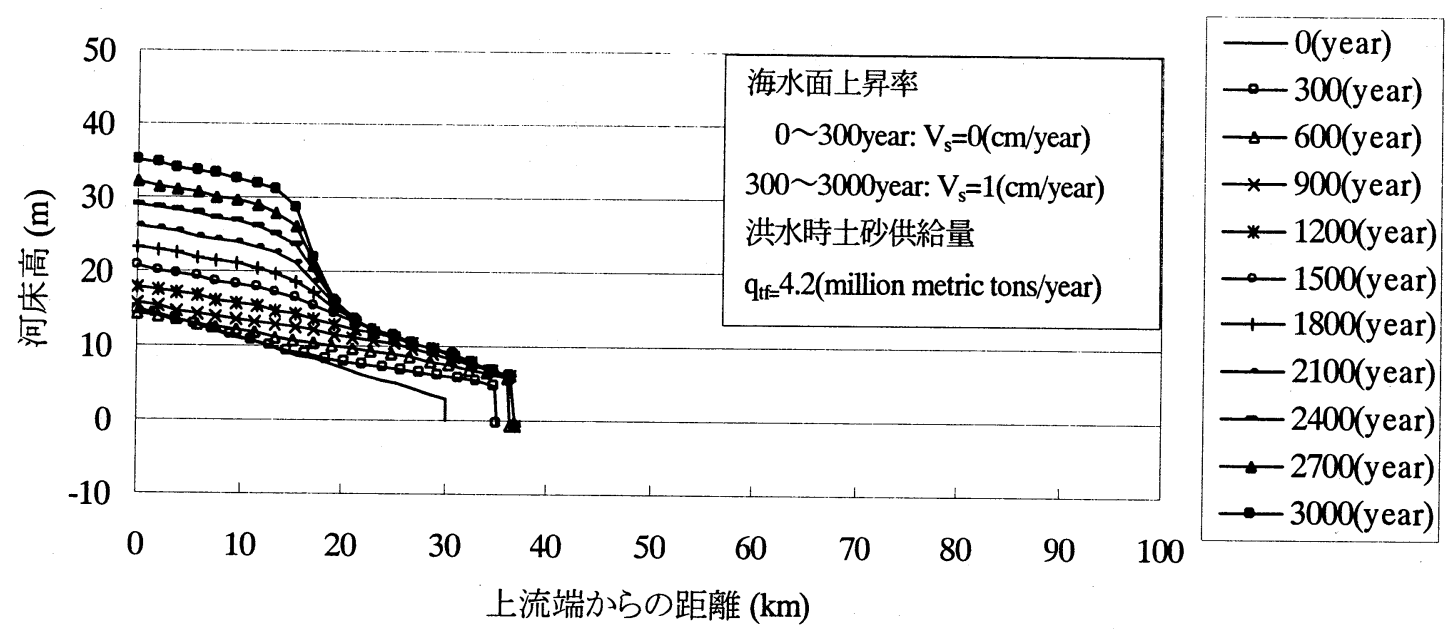

図-4 海水面上昇率が高く, 土砂供給量の少ない場合の河床形態の変化

デルタが後退する現象が見られる. また, 図-4に海水面 上昇率を $1(\mathrm{~cm} / \mathrm{year})$ として, 上流端からの土砂供給量を 半分にした場合 ( $\mathrm{q}_{\mathrm{tt}=} 4.2$ (million metric tons/year) $)$ の河床 形態の変化を示す. 海面上昇率が高く, 土砂供給量が少 ない場合には，湾が形成されることがわかる．これらの ことから河川の上流端からの土砂供給量と海水面の上昇 率のバランスによって, デルタの形態が決定されている と考えられる.

また，海水面上昇に対するデルタの応答はデルタのス ケールにも大きく依存すると考えられる．そこで，ス ケールの違う二つのデルタに対して本モデルを適応し, デル夕の応答の違いを検討する. 本計算では砂床河川を 仮定して, 粒径は0.25(mm)とした. また, デル夕の上流 端は移動境界とし, 海底領域の勾配はゼロとした. さら に, 川幅は満水時のShields応力が一定値を取るという仮 定のもとに, 流れの状態によって決定されている. 表-1 に本計算で用いた二つのデル夕の初期河川長, 河床勾配, 流域面積, 間欠度, 洪水時土砂供給量, 洪水時満水流量 を示す．表-1中の河川のパラメーターは河川長, 河川勾 配のみを既知のパラメーターとして与え, 流域面積, 洪 水時土砂供給量, 洪水時満水流量, 間欠度については以 下のように算出した. 流域面積は次式で表される流域の 形状係数 $\mathrm{F}\left(=\mathrm{A} / \mathrm{L}^{2}\right)$ を6として与え, 河川長から算出し た. 洪水時土砂供給量ついては年平均土砂供給量と等し いと仮定しSyvitski et al.(2000)によって提案された次式を 用いた.

$$
\overline{Q_{s}}=\alpha H^{3 / 2} A^{1 / 2}
$$

ここに, $\overline{\mathrm{Q}_{\mathrm{s}}}$ : 年平均土砂供給量, $\mathrm{H}$ : 堆積盆地の最大高 度, $\alpha$ : 係数 $\left(=2 \times 10^{-5}\right)$ である. また, 洪水時満水流 量および間欠度についてはDodov and Foufoula (2004)の研 究を参考に流域面積から決定した.

図-5に計算開始から 2000 年後から 4000 年後にわたって 海水面が1.5(cm/year)で上昇した場合におけるそれぞれの デル夕の河床形態の変化を示す. 大きいデルタにおいて はデル夕の進行は遅くなっているものの, 沖積領域にお ける河床形態の大きな変化はみられない, 一方, 小さい デル夕においては2000 4000年後にわたる海水面の上昇 により，沖積領域に土砂によって埋められるべき余剩の スペースが生まれており，そのため $5000 〜 8000$ 年後にか けてデル夕の後退現象が見られる. さらに，2000２500 年後にかけて $8(\mathrm{~cm} / \mathrm{year})$ の急激な海水面上昇が起こった 場合について，それぞれデル夕の河床形態の変化を図-6 に示す. 急激な海水面上昇後には, どちらの河川におい ても河口に湾が形成されており，その影響は小さいデル 夕の方がより上流まで及んでいることがわかる.これら のことから小さいデル夕は比較的海水面上昇の影響を受 けやすく, 海水面上昇によって河口域に湾を形成する可 能性があることがわかる. また，それとは対照的に大き い河川においては海水面上昇け影響は小さく，急激な海 水面上昇が長期間続かない限り, デル夕は前進し続ける と考えられる.

表-1 計算に用いたデルタのパラメーター

\begin{tabular}{ccccccc}
\hline & $\begin{array}{c}\text { 初期河川長 } \\
(\mathrm{km})\end{array}$ & 河川勾配 & $\begin{array}{c}\text { 流域面積 } \\
\left(\mathrm{km}^{2}\right)\end{array}$ & 間久度 & $\begin{array}{c}\text { 洪水時土砂供給量 } \\
(\mathrm{kg} / \mathrm{s})\end{array}$ & $\begin{array}{c}\text { 洪水時満水流量 } \\
\left(\mathrm{m}^{3} / \mathrm{s}\right)\end{array}$ \\
\hline \hline (a) & 800 & $1.0 \times 10^{-4}$ & 106667 & 0.21 & 4674 & 8224 \\
\hline (b) & 400 & $1.5 \times 10^{-4}$ & 26667 & 0.1 & 1518 & 4562 \\
\hline
\end{tabular}



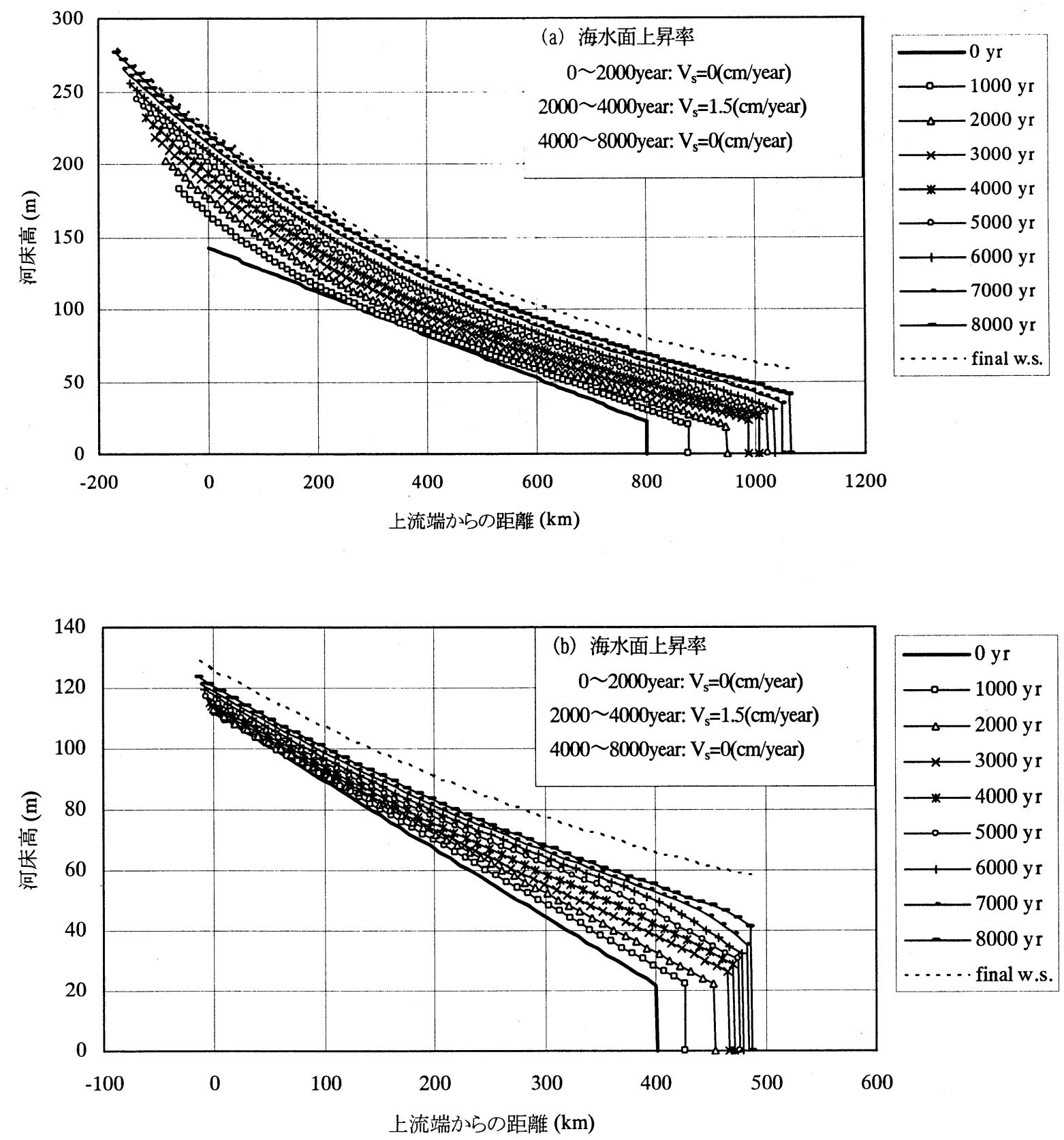

図-5 長期間の海水面上昇に対する大小のデルタの河床形態の変化

\section{4. 結論}

本研究によって河川の上流端からの土砂供給量と海水 面の上昇率のバランスによって，河口域でデルタが進行 し続けるかあるいはデル夕が後退し湾が形成されるかが 決定されていることが明らかになった. また，河川のス ケールによつて海小百上昇に刘する応答才゙大さく変化す ることがわかった. さらに, 近年問題となっている地球 温暖化による急激な海水面上昇が河口域のデル夕の形状 にどのような影響を及ぼすかを本モデルを用いて予測す ることが可能であると考えられる。

\section{謝辞}

本研究はNational Center for Earth-Surface Dynamics (Project Number:6217) の補助を受けている.

\section{参考文献}

Dodov, B. and E. Foufoula Georgiou. 2004 Fluvial processes and streamflow variability:Interplay in the scale-frequency continuum and implication for scaling.（投稿予定）

Engelund, F. and E. Hansen, 1972, A Monograph on Sediment Transport, Technisk Forlag, Copenhagen, Denmark.

Kostic, S. and Parker, G. 2003a Submitted Progradational sandmud deltas in lakes and reservoirs Part 1 . Theory and numerical 

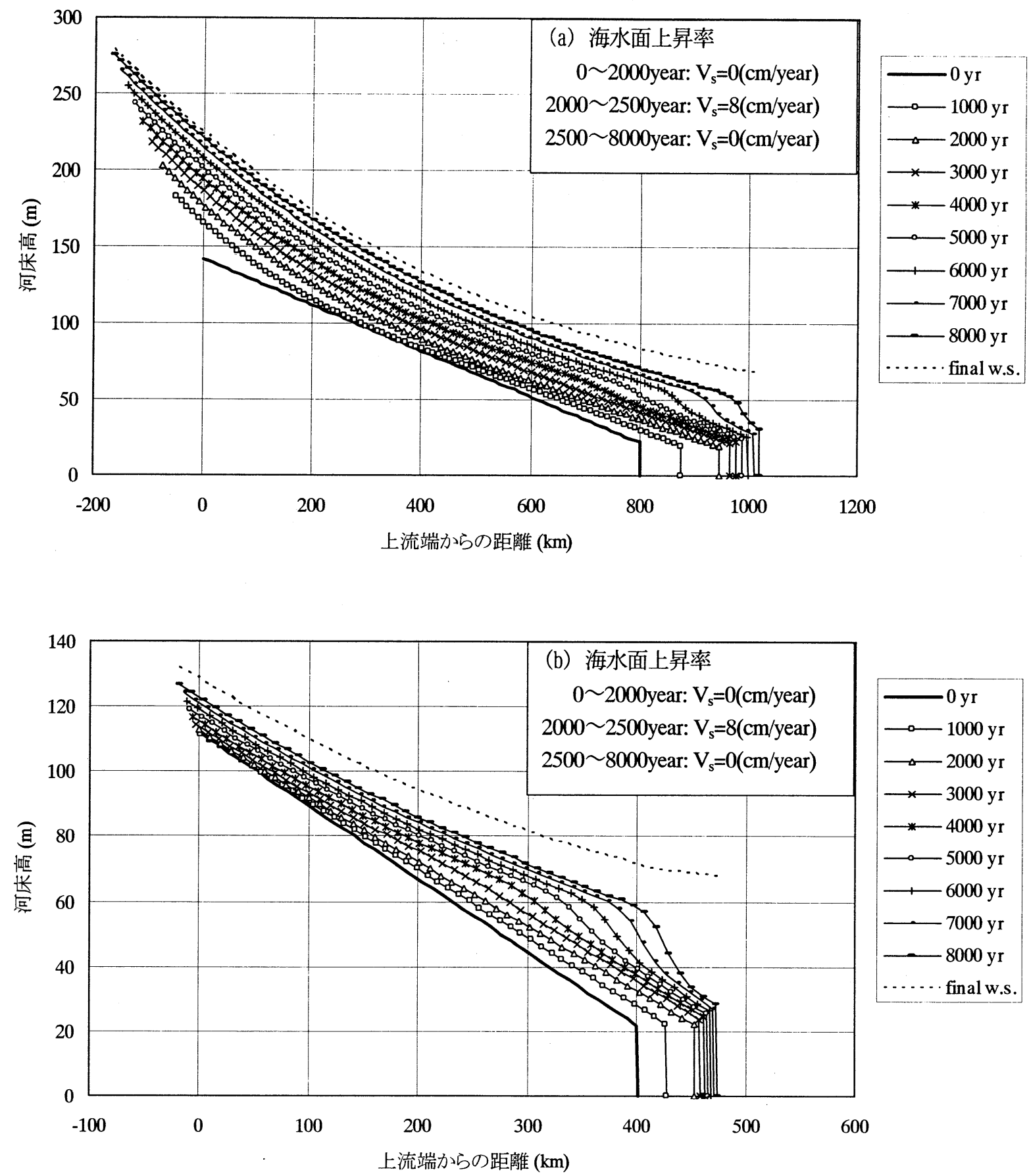

図-6 短期間の急激な海水面上昇に対する大小のデル夕の河床形態の変化

modeling. Journal of Hydraulic Research, 41(2).

Kostic, S. and Parker, G. 2003b Submitted Progradational sandmud deltas in lakes and reservoirs Part 2. Experiment and numerical simulation. Journal of Hydraulic Research, 41(2).

Muto, T. 2001 Shoreline autoretreat substantiated in flume experiment. Journal of Sedimentary Research, 71(2), 246-254.

Muto, T. and Steel, R. J. 1992 Retreat of the front in a prograding delta. Geology, 20, 967-970.

Parker, G and Muto, T. 2003 1D numerical model of delta response to rising sea level, Proceedings, $3^{\text {nd }}$ IAHR Symposium on River, Coastal and Estuarine Morphodynamics, 558-570. Syvitski, J.P., Morehead, M.D., Bahr, D.B. and Muler, T. 2000 Estimating fluvial sediment transport: The rating parameters. Water Resources Research, 36, No.9, 2747-2760.

Swenson, J. B., Voller, V. R., Paola, C., Parker, G. \& Marr, J. 2000 Fluvio-deltaic sedimentation: A generalized Stefan problem. European Journal of Applied Math., 11, 433-452. 